\title{
Patient Safety: \\ Contributions from a Task Analysis Study on Medicine Usage by Brazilians
}

\author{
Carla Spinillo, Stephania Padovani, and Cristine Lanzoni \\ PostGraduate Program in Design - Universidade Federal do Paraná -Departamento de Design \\ R. Gal. Carneiro, 460, - Edf. D. Pedro I - sala 811 - Centro - Curitiba - PR. Brazil \\ cgspineterra.com.br, s_padovani2@yahoo.co.uk, \\ cristinelanzoni@gmail.com
}

\begin{abstract}
Medicine misuse in Brazil is one of the most relevant health issues affecting millions of people. This paper discusses the results of a study on usage of five different medicines by 60 adult Brazilians. Problems in task performance occurred with all medicines, especially those requiring measuring doses and object manipulation. Deficiencies in the design of the medicine inserts were also found. The outcomes enable to conclude that improvements in the design of instructions for patients and of medicine inserts, as well as of medicine bottles/containers are necessary to facilitate their use by Brazilians.
\end{abstract}

Keywords: Medicine usage, Medicine inserts, Task analysis, Brazil.

\section{Introduction}

Brazil has a population of 190,706 million people and produces around 10,972 million medicines per year [1]. Although their purchase is regulated by the Ministry of Health [2], one may easily acquire medicines without prescriptions or assistance from health professionals. As a result, Brazilians are poised due to misuse of medicines. In the latest survey, from 1993 to $1996,57,748$ cases of medicine poison were registered in the country [3].

Taking a medicine may be a challenging task, demanding handling objects/devices (e.g., syringes, applicators), following instructions for dosage, storage and disposal, generally available in the medicine inserts. However, deficiencies in the graphic presentation of inserts may negatively affect patients' comprehension of the task [4-9].

Considering the aspects above, this paper briefly presents the results of a study conducted in Brazil on the effects of medicine inserts on task performance.

\section{The Study}

Sixty male and female adults participated in the study divided across the medicines tested (12 participants per medicine). Five medicines differing in the manner they 
should be taken were selected together with their inserts: (1) oral inhale capsule; (2) vaginal cream (female participants) (3) oral suspension (paediatric antibiotics); (4) insulin injection; and (5) nasal spray. For participants' safety, medicines were taken/used in a simulated manner demanding the same actions of the real task. Figure 1 shows the medicines used in the experiments and their inserts.

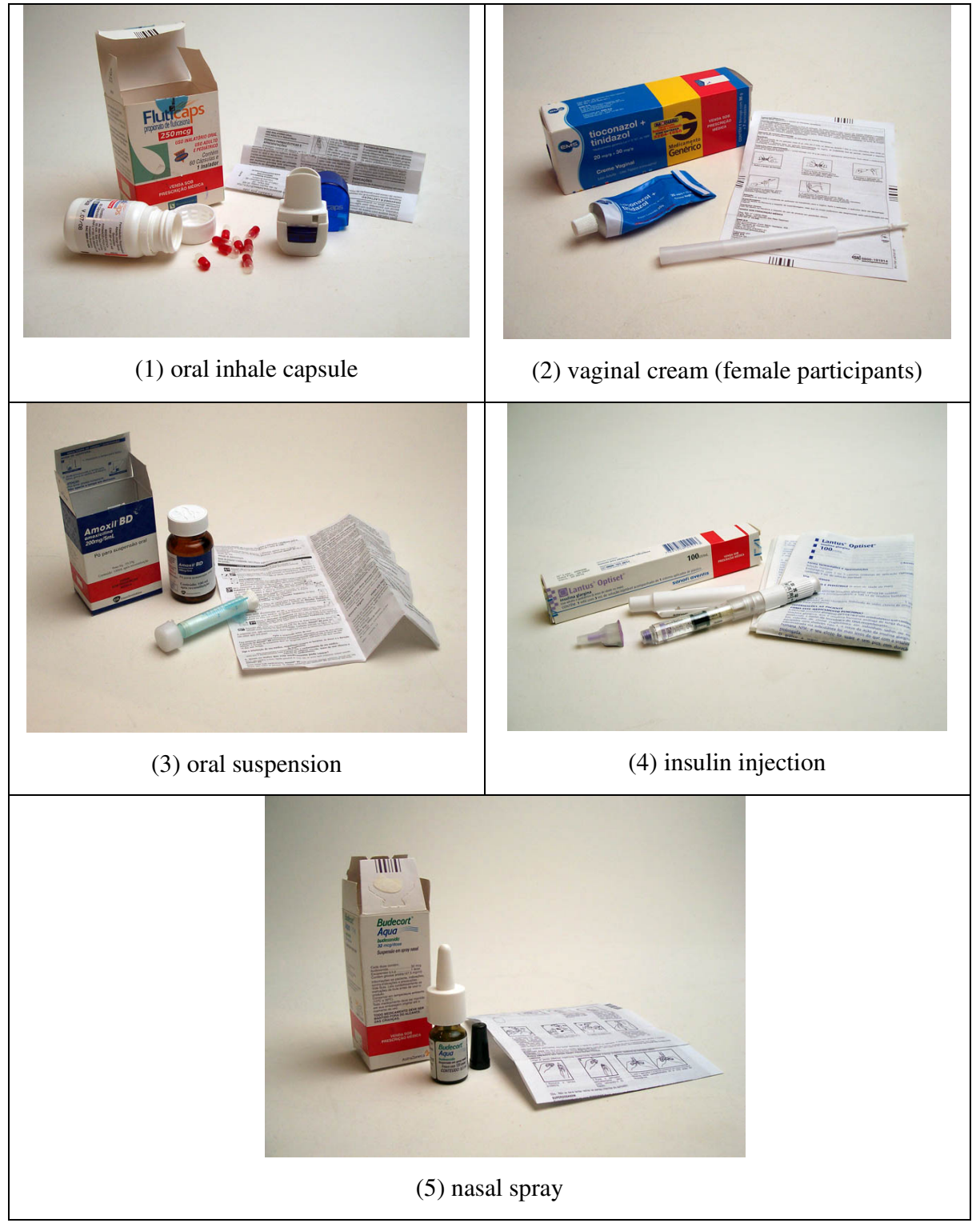

Fig. 1. Medicines used in the study 
Initially, each task was described according to the information available in the medicine inserts. Afterwards, participants were asked to take/use the medicine following the instructions in its insert. When they considered the task over, a semistructured interview was conducted regarding their impressions on their task performance and on the medicine inserts. Task performance was analysed as to the classification for human errors: (1) information processing, (2) action, and (3) verification [10] [11]. Subcategories were added to these classifications to suffice the study particularities on the task performances, as shown in Table 2. Data was analysed in a qualitative manner. The numbers presented here are only to indicate trends for discussion purpose.

Table 1. Classification for human errors used in the study and the subcategories proposed for analysing the results on task performance by participants

\begin{tabular}{|c|}
\hline \multirow{2}{*}{$\begin{array}{l}\text { 1 - Information processing errors } \\
\text { Internal (individual repertoire) }\end{array}$} \\
\hline \\
\hline Pi 1/ Wrong/Mistaken assumption \\
\hline External (insert/package/product) \\
\hline Pi 2l Information was not read/searched \\
\hline Pi 3l Information was incompletely read/searched \\
\hline Pi 4l Wrong information searched \\
\hline Pi 5I Information was searched but not found \\
\hline Pi 6l Information was searched and founded but not understood \\
\hline 2-Action errors \\
\hline A 1ITask/action was not performed \\
\hline A 21 Task/action was incompletely performed \\
\hline A 3I Task/action was performed in wrong/inappropriate moment \\
\hline A 4 I Very long or very short Task/action \\
\hline A 5I Task/action performed in a very little or very large amount/quantity \\
\hline A 61 Task/action in wrong direction \\
\hline A 7 I Wrong alignment \\
\hline A 8I Right task/action in wrong/mistaken object \\
\hline A 9l Right task/action but in a wrong part/component of a right object \\
\hline A 10| Wrong task/action in a right object \\
\hline A 11I Wrong task/action in a wrong object \\
\hline A 12I Selection not done \\
\hline A 13| Wrong selection done \\
\hline 3 - Verification errors \\
\hline V 1/ Verification not done \\
\hline V 2I Verification incompletely done \\
\hline V 31 Verification in a wrong moment \\
\hline V 4l Right verification in a wrong object \\
\hline V 5l Wrong verification in right object \\
\hline V 6I Wrong verification in wrong object \\
\hline V7l Verification in a very little or large amount/quantity \\
\hline
\end{tabular}




\section{Results and Discussion}

In the tasks' descriptions, the highest figure for necessary actions to take/use medicines was found in the oral inhale capsule $(\mathrm{N}=20)$. For the decision making process the highest figure was on the insulin injection $(\mathrm{N}=9)$, which also presented the highest figure $(\mathrm{N}=5)$ for conditional situations, together with oral suspension.

Regarding the experiments, results confirmed participants' difficulties on understanding medicine insert information, particularly on selection and verification of dosage. The highest figures for human error were found in insulin injection $(\mathrm{N}=162)$ and (3) oral suspension $(\mathrm{N}=75)$, as shown in Table 3. In addition, the inserts of these medicines showed major drawbacks in the graphic presentation of text, and lack of clarity in the visual instructions, which lead participants to loose interest in undertaking the task and to misinterpret instructions.

Table 2. Errors in task performance

\begin{tabular}{|c|c|c|c|c|}
\hline Medicine & $\begin{array}{c}\text { Errors } \\
\text { Information } \\
\text { processing }\end{array}$ & Action & Verification & Total \\
\hline (1) Oral inhale capsule & 20 & 30 & 2 & 52 \\
\hline (2) Vaginal cream & 7 & 13 & 0 & 30 \\
\hline (3) Insulin injection & 60 & 68 & 34 & 162 \\
\hline (4) Oral suspension & 32 & 39 & 4 & 75 \\
\hline (5) Nasal spray & 2 & 29 & 12 & 43 \\
\hline Total & 121 & 179 & 52 & \\
\hline
\end{tabular}

Results suggest that expected cognitive load during the process of taking a medicine might be beyond the instructions for medicine usage in the insert. These possibly lead patients to act intuitively, inferring the ways medicine can be taken/used. As a consequence, errors on manipulation / preparation of a medicine and on determining its right dosage occurred. It is worthwhile highlighting that if patients do not comply with the conditions to take/use/manipulate the medicine/medicine components, or do not make the proper decisions; their health may be severely compromised.

\section{Conclusions}

Despite the limited number of participants in this study, results indicated that Brazilians in general have difficulties in taking/using medicines, particularly those demanding manipulation of objects and preparation of dosage. Outcomes also permit questioning the effectiveness of medicine inserts produced in Brazil in communicating usage procedures.

Moreover, this study ratifies previous findings on the effect of graphic presentation of inserts on comprehension, and corroborates their influence on task performance.

Finally, it is worth pointing out the findings also suggest the design of medicine bottles/containers affects the ways instructions are followed. Although they were not the focus of this study, they influenced task performance of using/taking medicines. 
Thus, improvements not only in the design of medicine inserts, but also of medicine containers, seem to be necessary from a user-centred approach.

Acknowledgments. We would like to thank CNPq- Funding Agency of The Brazilian Ministry of Science and Technology, and The Brazilian Ministry of Health for supporting this research. We are also grateful to the participants for volunteering to the experiments.

\section{References}

1. IBGE. Instituto Brasileiro de Geografia e Estatística, Ministério do Planejamento. Dados estatísticos em saúde.,

http: / / www.ibge.gov.br/home/estatistica/economia/ economia_saude/

2. BRASIL, Ministério da Saúde. Portaria n.110, de 10 de março (1997), http: / /www . anvisa.gov.br/legis/portarias/110_97.htm (accessed Feburary 20, 2009)

3. Oliveira, E.A., Labra, M.E., Bermudez, J.: A produção pública de medicamentos no Brasil: uma visão geral. Cadernos de Saúde Pública, Rio de Janeiro 22(11), 2379-2389 (2006) (accessed Feburary 20, 2009)

4. Spinillo, C.G., Padovani, S., Miranda, F., Fujita, P.T.L.: Instruções visuais em bulas de medicamentos no Brasil: um estudo analítico sobre a representação pictórica da informação. In: $3^{\circ}$ Congresso Internacional de Design da Informação. SBDI, Curitiba (2007) (CD-ROM)

5. Spinillo, C.G., Padovani, S., Miranda, F.: Graphic and information aspects affecting the effectiveness of visual instructions in medicine inserts in Brazil. In: Proceedings of the AHFE International Conference 2008. USA Publishing, Louisville (2008)

6. Sless, D., Tyers, A.: Case history \# 5 I Panadol 24 Pack: new instructions for consumers. CRIA (2004a), http: / / www. communication.org.au/cria_publications / publication_id_89_1290110197.html

7. Sless, D., Tyers, A.: Labelling code of pratice: designing usable non-prescription medicine labels for consumers (2004b),

http: //www.communication.org.au/cria_publications

8. Waarde, K.: Visual information about medicines: providing patients with relevant information. In: Spinillo, C.G., Coutinho, S.G. (orgs.) Selected Readings of the Information Design International Conference 2003, pp. 81-89. SBDI, Recife (2004)

9. Wright, P.: Printed Instructions: Can research make a difference? In: Zwaga, H.J.G., Boersema, T., HoonHout, H.C.M. (eds.) Visual information for everyday use: Design and research perspectives, 45-66. Taylor \& Francis, London (1999)

10. Barber, C., Stanton, N.A.: Human error identification techniques applied to public technology: predictions compared with observed use. Applied Ergonomics 27(2), 119-131 (1996)

11. Rasmussen, J.: Human Error. In: Information Processing and human-machine interaction, pp. 140-169. North Holland, New York (1986) 